\title{
Study on the synthesis of the cyclopenta[f]indole core of raputindole $A$
}

\author{
Nils Marsch, Mario Kock and Thomas Lindel ${ }^{\star} \S$
}

\author{
Full Research Paper \\ Address: \\ Institute of Organic Chemistry, TU Braunschweig, Hagenring 30, \\ 38106 Braunschweig, Germany \\ Email: \\ Thomas Lindel ${ }^{*}$ - th.lindel@tu-braunschweig.de \\ * Corresponding author \\ § Fax: (+49) 531-391-7744; http://www.oc.tu-bs.de/lindel \\ Keywords: \\ gold-catalyzed reactions; heterocycles; indole alkaloids; natural \\ products; synthesis
}

\author{
Beilstein J. Org. Chem. 2016, 12, 334-342. \\ doi:10.3762/bjoc. 12.36 \\ Received: 05 November 2015 \\ Accepted: 05 February 2016 \\ Published: 23 February 2016 \\ Associate Editor: A. Kirschning \\ (c) 2016 Marsch et al; licensee Beilstein-Institut. \\ License and terms: see end of document.
}

\begin{abstract}
The raputindoles from the rutaceous tree Raputia simulans share a cyclopenta[f]indole partial structure the synthesis of which is subject of this investigation. An efficient route to a series of 1,5-di(indol-6-yl)pentenones was developed via Mo/Au-catalyzed Meyer-Schuster rearrangement of tertiary propargylic alcohol precursors. However, none of the enones underwent the desired Nazarov cyclization to a cyclopenta[f]indole. More suitable were 6-hydroxyallylated indolines which gave good yields of cyclopenta $[f]$ indolines after treatment with $\mathrm{SnCl}_{4}$, as soon as sterically demanding $\beta$-cyclocitral adducts were reacted. Most successful were $\mathrm{Pt}(\mathrm{II})$ and $\mathrm{Au}(\mathrm{I})$-catalyzed cyclizations of $N$-TIPS-protected indolin-6-yl-substituted propargylacetates which provided the hydrogenated tricyclic cyclopenta[f]indole core system in high yield.
\end{abstract}

\section{Introduction}

The raputindoles (1, raputindole A, Figure 1) from the rutaceous tree Raputia simulans Kallunki constitute a unique group of terpenoid bisindole natural products [1] sharing a linear cyclopenta[f]indole tricyclic partial structure. The cyclopenta $[f]$ indole system also occurs as partial structure of the nodulisporic acids [2], the shearinines [3-6] and janthitrems [7-10]. While work has been done on the total syntheses of herbindoles [11] and trikentrines [12], which contain angular cyclopenta[ $g]$ indole partial structures [13-29], there is only little known on the assembly of linear cyclopenta[f]indole systems.
Both existing approaches rely on the anellation of the pyrrole part to indene-based starting materials [30-33].

In this paper we discuss our experiences with the assembly of cyclopenta $[f]$ indole and -indoline systems (A, Scheme 1). A bond between the indole 5-position ( $4 \mathrm{a}$ in the resulting tricycle) and the quaternary center was to be formed. Ideally, anellation of a cyclopentane would be possible at an indole with an intact enamine partial structure (B, Scheme 1). Such an approach seemed possible, because we had already cyclized 6-prenoylin- 
<smiles>CC(C)=CC1CC(C)(/C=C/c2ccc3cc[nH]c3c2)c2cc3cc[nH]c3cc21</smiles>

\section{1: raputindole $\mathrm{A}$}

Figure 1: Bisindole alkaloid raputindole A (1) from the Amazonian tree Raputia simulans.

dole to a mixture of cyclopenta[f]- and -[ $g]$ indoles in a Nazarovtype reaction [34]. By installation of a triflyloxy group in the indole 5-position, Pd-catalyzed cyclization also would become possible. As an alternative to the cyclization of enones, Lewis acid-induced cyclizations of allylic alcohols could afford the desired cyclopenta[ $f]$ indole system $(\mathbf{C}, \mathbf{D})$. Here, it was unclear whether the indole enamine section would be tolerated or have to be reduced prior to cyclization. Finally, propargyl alcohol derivatives (E) were to be investigated as substrates of $\mathrm{Pt}(\mathrm{II})$ and $\mathrm{Au}(\mathrm{I})$-catalyzed reactions. All of the investigated building blocks were to be obtained from 6-iodoindole (2), which was synthesized via the Batcho-Leimgruber route and purified by sublimation [34].

\section{Results and Discussion}

Di(indol-6-yl)pentenones. Regarding the investigation of 6-acryloylindoles, we aimed at the synthesis of methylbranched di(indol-6-yl)pentenones from the beginning, which already included the second indole moiety of raputindole A (1). Boc protection of 6-iodoindole (2) [35], Sonogashira reaction of 3 with TMS-acetylene, and desilylation gave the N-protected alkynylindole 4 in excellent yield (Scheme 2). Boc-iodoindole 3 was also the precursor of the coupling partner, ketone $\mathbf{6}$, which was synthesized via Heck reaction with but-3-en-2-ol (5, 89\%) in the presence of $\mathrm{LiCl}$, inspired by a procedure by Camp and coworkers [36].

Propargyl bisindole 7 was obtained after conversion of $\mathbf{4}$ ( 2 equiv) to the magnesium acetylide (iPrMgCl in THF) and Grignard reaction with ketone 6. Due to the presence of Boc-protected indole nitrogens an acid-catalyzed Meyer-Schuster rearrangement was dismissed. Instead, a transition metal-catalyzed rearrangement employing $1 \mathrm{~mol} \%$ of $\mathrm{MoO}_{2}(\mathrm{acac})_{2} /\left[\mathrm{Au}\left(\mathrm{PPh}_{3}\right) \mathrm{Cl}\right] / \mathrm{AgOTf}$ [37] afforded the $\alpha, \beta$-unsaturated ketone 8 as a 2:1 mixture of $E / Z$ isomers ( $86 \%$ ), which could not be separated by HPLC due to a reisomerization upon concentration of the fractions. When bisindole 8 was subjected to $\mathrm{AlCl}_{3}$, no cyclization product was observed and only deprotection occurred. This was somewhat surprising, because treatment of 6-prenoylindole with $\mathrm{AlCl}_{3}$ in 1,2-dichlorobenzene at $150{ }^{\circ} \mathrm{C}$ had induced Nazarov cyclization affording a mixture of regioisomeric cyclopenta[f]- and -[g]indolones [34]. Kern and coworkers had obtained an indanone under the same conditions [38]. Other attempts to cyclize 8 also failed.

We turned to Pd-catalyzed reductive cyclization. As precursor, a 5-triflyloxyindole was preferred over a 5-bromoindole, because 2-iodo-5-methyl-4-nitrophenol (11, Scheme 3), to be used in the Batcho-Leimgruber protocol, appeared to be more readily accessible than 1-bromo-2-iodo-5-methyl-4-nitrobenzene. Moreover, aryl triflates have been used in intramolecular cyclization reactions with $\alpha, \beta$-unsaturated ketones to obtain indanones and dihydronaphthones [39,40]. Aminophenol 9 was converted to iodophenol $\mathbf{1 0}$ in good yield through a Sandmeyer reaction (Scheme 3) [41]. Various nitration conditions were tested, yet only the use of concentrated $\mathrm{HNO}_{3}$ in $\mathrm{CH}_{2} \mathrm{Cl}_{2}$, as reported by Chancellor and coworkers [42], gave nitrophenol 11

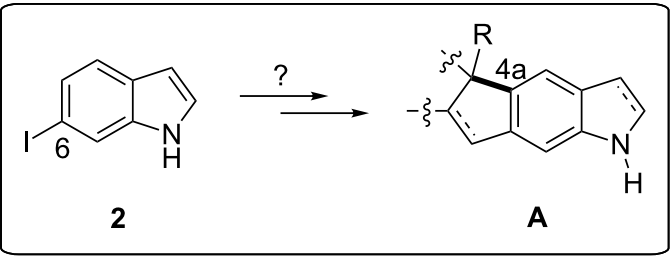<smiles>[R]C(C)=CC(=O)c1cc2c(ccn2C(C)(C)C)cc1[X]</smiles>

B<smiles>[R]n1ccc2ccc([C@@H](O)C3=C(C)CCCC3(C)C)cc21</smiles>

C<smiles></smiles>

D

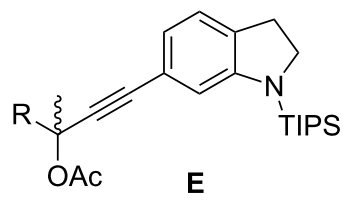




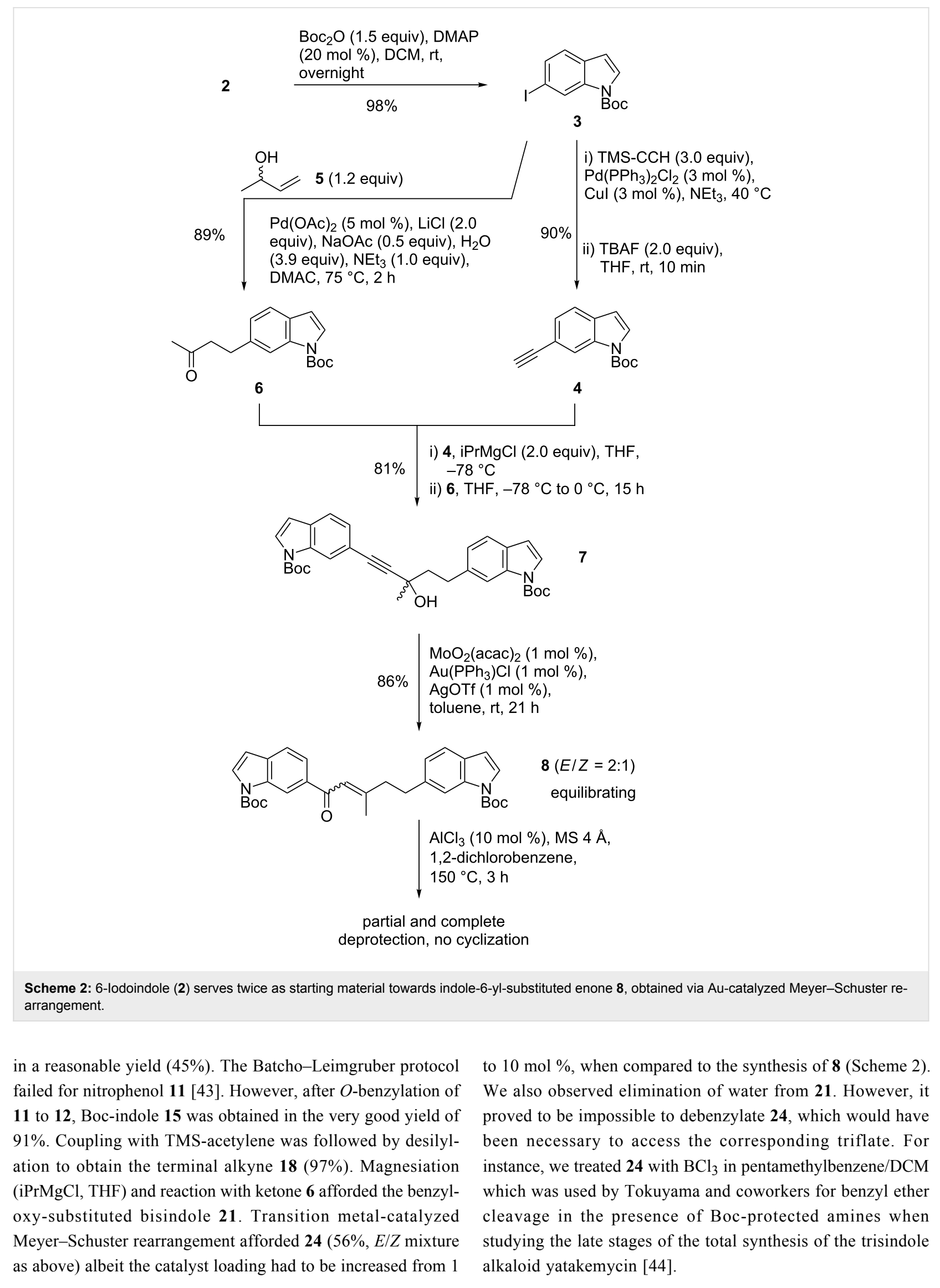




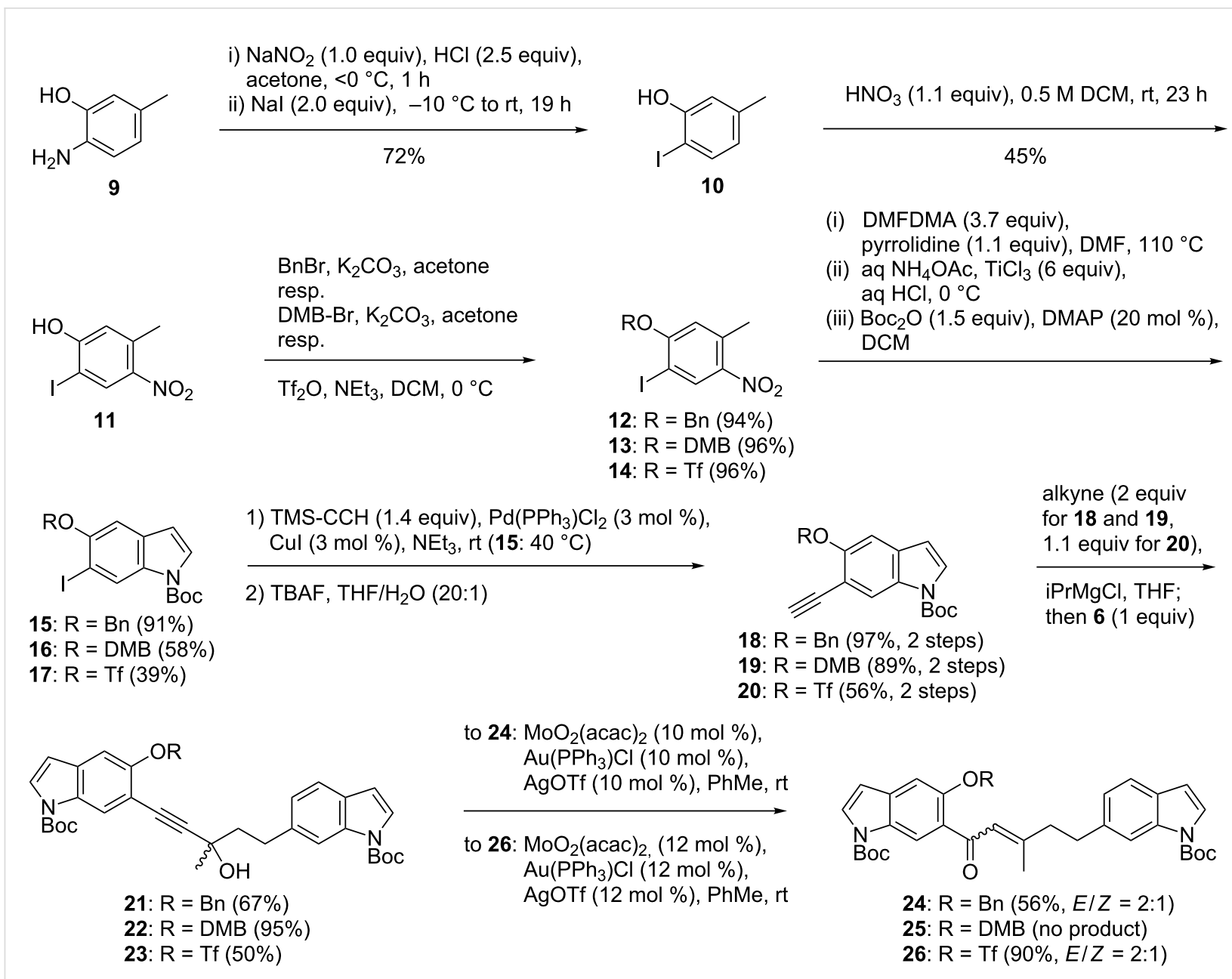

Scheme 3: Assembly of 5-oxygenated bisindolylpentenones. DMB: 3,4-dimethoxybenzyl, DMFDMA: N,N-dimethylformaldehyde dimethyl acetal.

As an alternative, the 3,4-dimethoxybenzyl (DMB) protecting group was installed (13). We favored the DMB over the related PMB group, because the oxidation potential of DMB ethers is lower and the cleavage was expected to be more facile [45]. Indole synthesis from DMB-protected 13 and subsequent Boc protection afforded 16 (58\%). Alkynylation and desilylation of $\mathbf{1 6}$ to 19 and coupling of $\mathbf{1 9}$ with ketone $\mathbf{6}$ proceeded smoothly providing the DMB-protected bisindole 22 in $18 \%$ overall yield over seven steps (Scheme 3). However, in the presence of the DMB group, the Meyer-Schuster rearrangement of alkyne 22 to the envisaged ketone 25 failed. Mixtures of elimination products dominated along with the cleavage of the DMB ether. Meyer-Schuster products could also be observed, but in small amounts and not as pure compounds.

It is worth mentioning that treatment of $\mathbf{2 2}$ with DDQ led to removal of the DMB group, affording the major product 27 (23\%) exhibiting a keto group in the benzylic indole position (Scheme 4). This transformation might become useful in a future total synthesis of raputindole A (1) as a reduction-elimination sequence of the benzylic ketone could be used to introduce the olefinic double bond.

Since neither from $\mathbf{2 2}$ nor from $\mathbf{2 4}$ the indole-5-OH group could be liberated, we turned back to the originally dismissed idea of installing the triflate group prior to indole assembly. There are no 5-triflyloxy-6-iodoindoles described in the literature. First, iodonitrophenol 11 was converted to triflate 14 in $96 \%$ yield. Subsequent Batcho-Leimgruber synthesis afforded the 6-iodo5-triflyloxyindole, which was Boc-protected (17, 39\%, three steps, Scheme 3). Sonogashira coupling occurred preferably at the iodinated 6-position affording 6-alkynylindole $\mathbf{2 0}$ after desilylation (56\%). The reaction with ketone 6 after magnesiation led to propargylic alcohol $23(50 \%)$. Interestingly, the Meyer-Schuster rearrangement of triflated alkyne 23 to ketone 26 proceeded in the highest yield of all our Meyer-Schuster rearrangements. With triflated $\alpha, \beta$-unsaturated ketone $\mathbf{2 6}$ in hand, we attempted reductive Heck cyclizations to the raputindole 


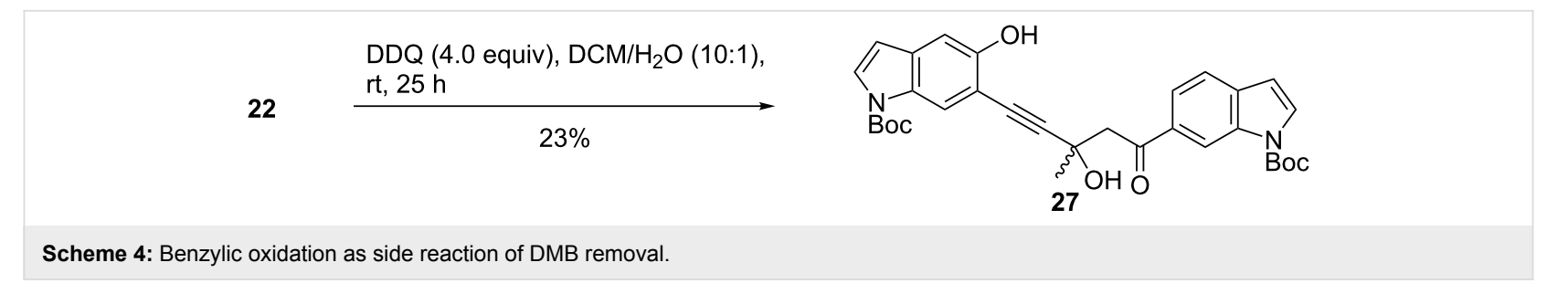

core structure. For instance, we employed $\mathrm{Pd}(\mathrm{dba})_{2}(12 \mathrm{~mol} \%)$, QPhos (24 mol \%), and $\mathrm{NEt}_{3}$ (1.20 equiv) in DMF at $100{ }^{\circ} \mathrm{C}$. Unfortunately, all reactions gave intractably complex mixtures. ${ }^{1} \mathrm{H}$ and ${ }^{19} \mathrm{~F}$ NMR analysis suggested that cleavage of at least one Boc-protecting group had occurred. Additionally, the triflate was still visible in the ${ }^{19} \mathrm{~F}$ NMR spectrum, thus indicating that oxidative addition to the Pd catalyst had not taken place.

At this point, we abandoned our attempts of assembling the cyclopenta $[f]$ indole unit of raputindole A (1) starting from Bocprotected indoles. None of the investigated bisindolylpentenones $\mathbf{8 , 2 4}$, or $\mathbf{2 6}$ could be cyclized to a cyclopentaindole. At least, we learned how to synthesize the open-chain molecules and also their propargylic precursors.
Cyclization of allyl cations. Besides Nazarov and reductive Pd-catalyzed cyclizations there was the possibility of generating an allyl cation which would have to undergo cyclization to the cyclopenta[f]indole. There are not many examples of cyclopentene anellation by cyclization of aryl-substituted allyl cations. High yields were reported by Alvarez-Manzaneda et al. in the course of their total synthesis of taiwaniaquinone $\mathrm{H}$. They induced the cyclization by treatment of arylvinylcarbinols with the mild Lewis acid $\mathrm{SnCl}_{4}$, which were synthesized by hydroxyalkylation with $\beta$-cyclocitral [46].

Hydroxyalkylation of Boc-protected 6-iodoindole (3) with 6- $\beta$ cyclocitral (30) was possible after iodine/magnesium exchange, affording adduct 31 (Scheme 5). However, treatment of $\mathbf{3 1}$ with

i) LHMDS, THF, $-78^{\circ} \mathrm{C}, 30 \mathrm{~min}$

ii) $\operatorname{TIPSCl},-78^{\circ} \mathrm{C}, 20 \mathrm{~min}$, to rt, $1 \mathrm{~h} R=$ TIPS

2

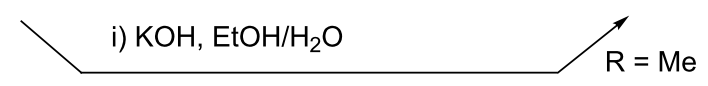

ii) $\mathrm{Me}_{2} \mathrm{SO}_{4}$, acetone, $5 \mathrm{~min}$, rt

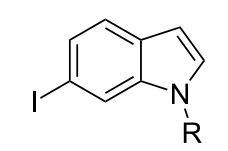

3: $\mathrm{R}=\mathrm{Boc}$

28: $\mathrm{R}=\mathrm{CH}_{3}(97 \%)$

29: $R=$ TIPS $(93 \%)$

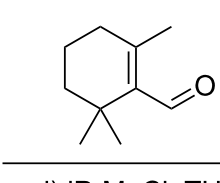

i) $\mathrm{PrMgCl}, \mathrm{THF}, \mathrm{rt}, 2 \mathrm{~h}$

ii) $30, \mathrm{rt}$<smiles>[R]n1ccc2ccc([C@@H](O)C3=C(C)CCCC3(C)C)cc21</smiles>

31: $\mathrm{R}=\mathrm{Boc}(28 \%)$

32: $\mathrm{R}=\mathrm{CH}_{3}(64 \%)$

33: $\mathrm{R}=$ TIPS $(48 \%)$

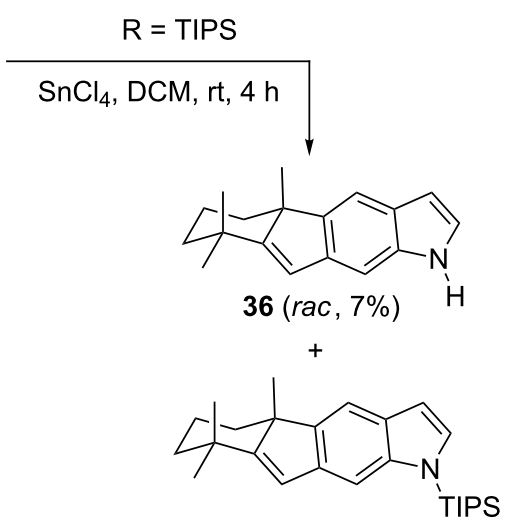

$37(\mathrm{rac}, 2 \%)$ 
$\mathrm{SnCl}_{4}$ in DCM did not afford any defined product. This changed after replacement of the Boc by a methyl group. The 6-hydroxyalkylated $N$-methylindole 32 (64\%) was prepared from 6-iodo- $N$-methylindole (28) with $\beta$-cyclocitral (30). The subsequent treatment of $\mathbf{3 2}$ with $\mathrm{SnCl}_{4}$ in DCM afforded a 1:2 mixture of regioisomeric indeno[1,2-f]indole $34(11 \%)$ and indeno[2,1-g]indole 35 (21\%).

For the corresponding $N$-TIPS-protected indole 33, obtained from 29, yields of tetracyclic products 36 (7\%) and 37 (2\%) were very low and we observed the loss of the TIPS protecting group. Noteworthy, we did not detect regioisomeric indeno[2,1$g$ ]indole products when starting from $\mathbf{3 3}$, which points at a shielding effect of the TIPS group towards the indole 7-position.
Since the $\mathrm{SnCl}_{4}$-mediated cyclization yields with indoles were much lower than those obtained with benzene derivatives, we investigated the behavior of indolines which lack the reactive enamine moiety. We also abandoned the use of Boc-protecting groups. Reduction of 6-iodoindole with $\mathrm{NaBH}_{3} \mathrm{CN}$ in $\mathrm{HOAc}$ afforded 6-iodoindoline (38, 90\%) [47], which was subsequently TIPS-protected (39, Scheme 6).

Hydroxyalkylation of $\mathbf{3 9}$ with $\beta$-cyclocitral (30) gave cyclization precursor $40(68 \%)$. We were pleased to find that this time the $\mathrm{SnCl}_{4}$-induced cyclization afforded the desilylated tetracyclic indeno[1,2-f]indoline 41 in high yield (82\%). We did not detect any regioisomer, probably because the TIPS group was still in place in the regioselecting step. In order to obtain a tricyclic cyclopentaindoline, the propargylic alcohol 43 (96\%)

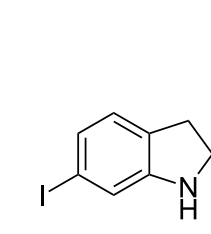

38 i) LHMDS, THF,$-78^{\circ} \mathrm{C}$,

$30 \mathrm{~min}$

ii) $\mathrm{TIPSCl},-78^{\circ} \mathrm{C}$,

$20 \mathrm{~min}$, to rt, $1 \mathrm{~h}$

$92 \%$<smiles>S=[In]N1CCc2ccc(I)cc21</smiles>

39

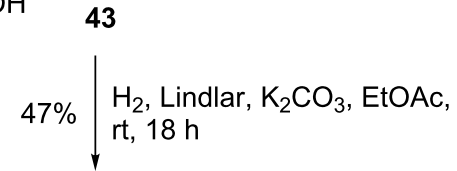<smiles></smiles><smiles>CCCC1(C)C=Cc2cc3c(cc21)CCN3</smiles> 
was synthesized by Sonogashira coupling of $N$-TIPS-6-iodoindoline (39) and $\mathbf{4 2}$. Conversion of $\mathbf{4 3}$ to the $(Z)$-allylic alcohol 44 by modified $\left(\mathrm{K}_{2} \mathrm{CO}_{3}\right)$ Lindlar hydrogenation $(47 \%)$ followed. Treatment of $\mathbf{4 4}$ with $\mathrm{SnCl}_{4}$ in DCM afforded cyclopenta $[f]$ indoline 45 , albeit in the rather disappointing yield of $11 \%$.

A reason for the much better yield of $\beta$-cyclocitral adduct $\mathbf{4 1}$ when compared to $\mathbf{4 5}$ may be a conformational restriction of the allyl cation, caused by the geminal methyl groups of $\mathbf{4 0}$. The intermediate is probably kept in the cisoid conformation required for the cyclization. Thus, switching from indole to indoline and changing the N-protecting group significantly improved the yield for the cyclocitral adduct, but this still does not appear to be sufficient for a strategy towards raputindole A (1).

Cyclization of propargylacetates. Key progress came when applying platinum and gold chemistry to propargylacetates $\mathbf{4 6}$ and 47 (Scheme 7), which were obtained by Sonogashira alkynylations of $N$-TIPS-6-iodoindoline (39), followed by acetylation (for experimental procedures, see Supporting Information File 1). Xuegong She and coworkers had obtained indanone derivatives from arylpropargylic esters in a $\mathrm{Pt}(\mathrm{II})$-catalyzed reaction for which they propose a formal rearrangement of the acetoxy group, followed by cyclization [48]. When we treated 46 and 47 with $\mathrm{PtI}_{2}(10 \mathrm{~mol} \%)$ in a $\mathrm{CO}$ atmosphere at elevated temperature $\left(\mathrm{PhMe}, 80^{\circ} \mathrm{C}\right)$ we indeed obtained the tricyclic cyclopentanones 48 and 49 , respectively. Yields were moderate in both cases (33\% and $29 \%$ ), but already better than in the case of the $\mathrm{SnCl}_{4}$-induced cyclization of $(Z)$-allylic alcohol 44 (Scheme 6). We only isolated the cyclopentanones, formed from the corresponding cyclopentenyl acetates. Presumably, the propargylacetate first undergoes a [3,3]-sigmatropic shift to the allenyl acetate, followed by a Pt(II)-catalyzed cyclization to the tricycle.

When propargylacetates 46 and $\mathbf{4 7}$ were treated with catalytic amounts of $\mathrm{Au}\left(\mathrm{PPh}_{3}\right) \mathrm{Cl} / \mathrm{AgBF}_{4}$ (DCM, rt, dark), cyclopenta $[f]$ indolines $\mathbf{5 0}$ and $\mathbf{5 1}$ were isolated in even better yields. It proved to be beneficial to filter the catalyst solution through a pad of Celite prior to addition of the starting material to remove $\mathrm{AgCl}$. In that way we reached an $81 \%$ yield of tricycle 50. The acetoxy group again formally underwent a 1,3-shift to the benzylic position, which may also be based on a [3,3]-sigmatropic rearrangement. Alternatively, for a similar 1,3-shift, Nolan and coworkers proposed two sequential 1,2-shifts to occur after $\pi$-complexation of the triple bond by $\mathrm{Au}(\mathrm{I})$ [49]. Methanolysis $(\mathrm{NaOMe} / \mathrm{MeOH})$ of cyclopentenylacetate 50 afforded cyclopenta[f]indolinone 48 (96\%).

\section{Conclusion}

It was our goal to explore how to efficiently assemble the cyclopenta[f]indole section present in the natural product raputindole A (1). As long as the cyclopentane ring would not be installed, it was indeed possible to work with 2,3-unsubstituted, $N$-Bocprotected indoles. In particular, the Mo/Au-catalyzed Meyer-Schuster rearrangement of propargylalcohols 7, 21, and 23 worked nicely, even in the presence of a triflyloxy group.

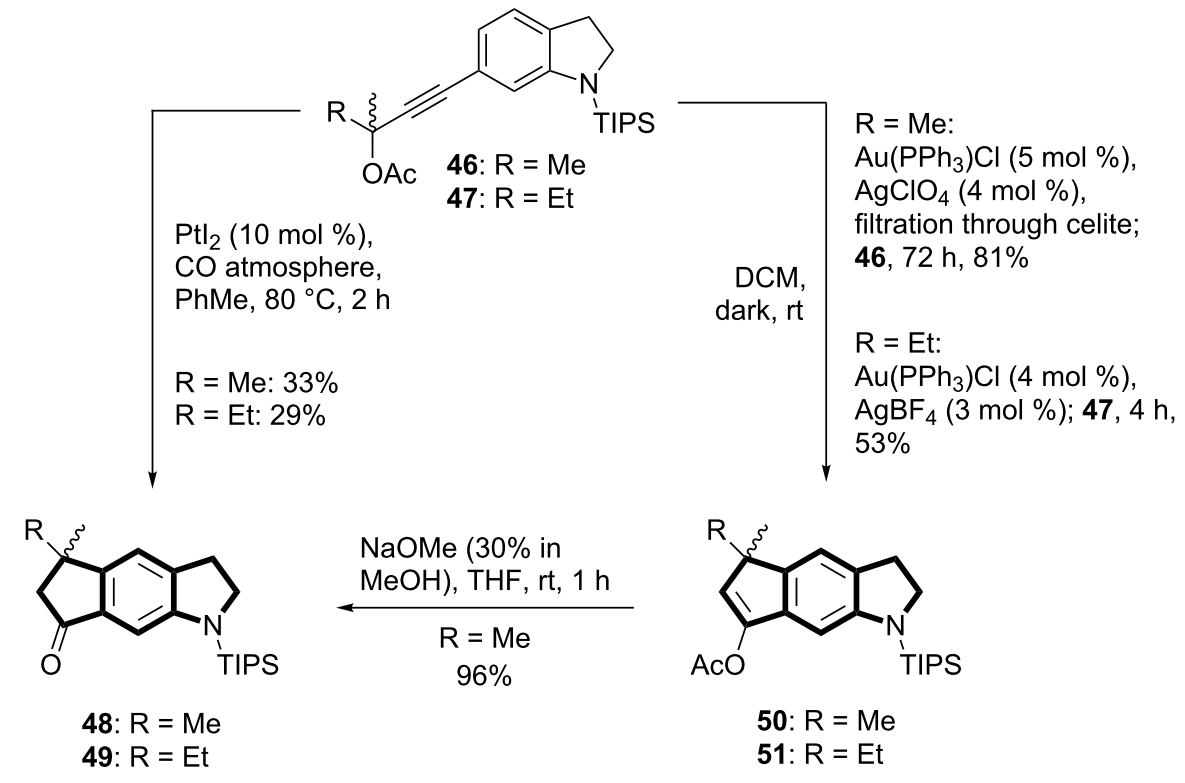

Scheme 7: $\mathrm{Pt}(\mathrm{II})$ and $\mathrm{Au}(\mathrm{I})$-catalyzed cyclizations of propargylacetates $\mathbf{4 6}$ and $\mathbf{4 7}$ afforded cyclopenta[f]indolinones $\mathbf{4 8}$ and $\mathbf{4 9}$, and tricyclic cyclopentenylacetates $\mathbf{5 0}$ and $\mathbf{5 1}$. 
However, all attempts of cyclization failed with the Boc-protected bisindoles. Two modifications changed things for the better regarding the cyclization: replacement of the Boc- by a non-coordinating TIPS-protecting group and the use of indolines instead of sensitive indoles. Cyclopentane anellation by $\mathrm{SnCl}_{4}$-induced cyclization of phenylvinylcarbinols became possible, at least for the sterically congested $\beta$-cyclocitral adduct 40 of $N$-TIPS-indoline. The less sterically demanding substrate $\mathbf{4 4}$ gave lower yields. Experiments employing $\mathrm{Au}(\mathrm{I})$ and $\mathrm{Pt}(\mathrm{II})$ catalysts point at how to continue, since tricycles $\mathbf{4 8}$, 49, and 50 were obtained in good yields. We will now investigate the synthesis and $\mathrm{Au}(\mathrm{I})$ and $\mathrm{Pt}(\mathrm{II})$-catalyzed cyclizations of TIPS-protected bisindolines, following a modified retrosynthesis of raputindole A (1).

\section{Supporting Information}

\section{Supporting Information File 1}

Experimental procedures and NMR spectra.

[http://www.beilstein-journals.org/bjoc/content/

supplementary/1860-5397-12-36-S1.pdf]

\section{Acknowledgements}

We thank Merck KGaA (Darmstadt, Germany) for the generous gift of chromatography materials. The BASF Group (Ludwigshafen, Germany) and Honeywell Specialty Chemicals Seelze $\mathrm{GmbH}$ (Seelze, Germany) are thanked for the donation of solvents.

\section{References}

1. Vougogiannopoulou, K.; Fokialakis, N.; Aligiannis, N.; Cantrell, C.; Skaltsounis, A.-L. Org. Lett. 2010, 12, 1908-1911. doi:10.1021/ol100584w

2. Ondeyka, J. G.; Helms, G. L.; Hensens, O. D.; Goetz, M. A.; Zink, D. L.; Tsipouras, A.; Shoop, W. L.; Slayton, L.; Dombrowski, A. W.; Polishook, J. D.; Ostlind, D. A.; Tsou, N. N.; Ball, R. G.; Singh, S. B. J. Am. Chem. Soc. 1997, 119, 8809-8816. doi:10.1021/ja971664k

3. Belofsky, G. N.; Gloer, J. B.; Wicklow, D. T.; Dowd, P. F. Tetrahedron 1995, 51, 3959-3968. doi:10.1016/0040-4020(95)00138-X

4. Xu, M.; Gessner, G.; Groth, I.; Lange, C.; Christner, A.; Bruhn, T.; Deng, Z.; Li, X.; Heinemann, S. H.; Grabley, S.; Bringmann, G.; Sattler, I.; Lin, W. Tetrahedron 2007, 63, 435-444. doi:10.1016/j.tet.2006.10.050

5. Smetanina, O. F.; Kalinovsky, A. I.; Khudyakova, Y. V.; Pivkin, M. V.; Dmitrenok, P. S.; Fedorov, S. N.; Ji, H.; Kwak, J.-Y.; Kuznetsova, T. A. J. Nat. Prod. 2007, 70, 906-909. doi:10.1021/np060396d

6. Gallagher, R. T.; Latch, G. C.; Keogh, R. G. Appl. Environ. Microbiol. 1980, 39, 272-273.

7. Lauren, D. R.; Gallagher, R. T. J. Chromatogr. 1982, 248, 150-154. doi:10.1016/S0021-9673(00)83747-4
8. de Jesus, A. E.; Steyn, P. S.; van Heerden, F. R.; Vleggaar, R. J. Chem. Soc., Perkin Trans. 1 1984, 697-701. doi:10.1039/p19840000697

9. Wilkins, A. L.; Miles, C. O.; Ede, R. M.; Gallagher, R. T.; Munday, S. C J. Agric. Food Chem. 1992, 40, 1307-1309. doi:10.1021/jf00020a002

10. Herb, R.; Carroll, A. R.; Yoshida, W. Y.; Scheuer, P. J.; Paul, V. J. Tetrahedron 1990, 46, 3089-3092. doi:10.1016/S0040-4020(01)88399-X

11. Capon, R. J.; Macleod, J. K.; Scammels, P. J. Tetrahedron 1986, 42, 6545-6550. doi:10.1016/S0040-4020(01)88117-5

12. Muratake, H.; Mikawa, A.; Natsume, M. Tetrahedron Lett. 1992, 33, 4595-4598. doi:10.1016/S0040-4039(00)61322-9

13. Macleod, J. K.; Monahan, L. C. Tetrahedron Lett. 1988, 29, 391-392. doi:10.1016/S0040-4039(00)80105-7

14. Boger, D. L.; Zhang, M. J. Am. Chem. Soc. 1991, 113, 4230-4234. doi:10.1021/ja00011a026

15. Muratake, H.; Natsume, M. Tetrahedron Lett. 1989, 30, 5771-5772. doi:10.1016/S0040-4039(00)76193-4

16. Muratake, H.; Watanabe, M.; Goto, K.; Natsume, M. Tetrahedron 1990, 46, 4179-4192. doi:10.1016/S0040-4020(01)86755-7

17. Muratake, H.; Seino, T.; Natsume, M. Tetrahedron Lett. 1993, 34 , 4815-4818. doi:10.1016/S0040-4039(00)74096-2

18. Muratake, H.; Mikawa, A.; Seino, T.; Natsume, M. Chem. Pharm. Bull. 1994, 42, 854-864. doi:10.1248/cpb.42.854

19. Yasukouchi, T.; Kanematsu, K. Tetrahedron Lett. 1989, 30 , 6559-6562. doi:10.1016/S0040-4039(01)89021-3

20. Jackson, S. K.; Banfield, S. C.; Kerr, M. A. Org. Lett. 2005, 7, 1215-1218. doi:10.1021/ol047498k

21. Jackson, S. K.; Kerr, M. A. J. Org. Chem. 2007, 72, 1405-1411. doi:10.1021/jo062350v

22. Buszek, K. R.; Brown, N.; Luo, D. Org. Lett. 2009, 11, 201-204. doi:10.1021/ol802425m

23. Chandrasoma, N.; Brown, N.; Brassfield, A.; Nerurkar, A.; Suarez, S.; Buszek, K. R. Tetrahedron Lett. 2013, 54, 913-917. doi:10.1016/j.tetlet.2012.11.125

24. Brown, N.; Luo, D.; Decapo, J. A.; Buszek, K. R. Tetrahedron Lett. 2009, 50, 7113-7115. doi:10.1016/j.tetlet.2009.09.083

25. Silva, L. F., Jr.; Craveiro, M. V. Org. Lett. 2008, 10, 5417-5420. doi:10.1021/ol8023105

26. Silva, L. F., Jr.; Craveiro, M. V.; Tébéka, I. R. M. Tetrahedron 2010, 66, 3875-3895. doi:10.1016/j.tet.2010.03.089

27. Saito, N.; Ichimaru, T.; Sato, Y. Org. Lett. 2012, 14, 1914-1917. doi:10.1021/ol300571b

28. Tébéka, I. R. M.; Longato, G. B.; Craveiro, M. V.; de Carvalho, J. E.; Ruiz, A. L. T. G.; Silva, L. F., Jr. Chem. - Eur. J. 2012, 18, 16890-16901. doi:10.1002/chem.201202413

29. Liu, W.; Lim, H. J.; RajanBabu, T. V. J. Am. Chem. Soc. 2012, 134, 5496-5499. doi:10.1021/ja3004733

30. Magnus, P.; Mansley, T. E. Tetrahedron Lett. 1999, 40, 6909-6912. doi:10.1016/S0040-4039(99)01355-6

31. Smith, A. B., III; Davulcu, A. H.; Kürti, L. Org. Lett. 2006, 8, 1669-1672. doi:10.1021/ol0602912

32. Smith, A. B., III; Davulcu, A. H.; Cho, Y. S.; Ohmoto, K.; Kürti, L.; Ishiyama, H. J. Org. Chem. 2007, 72, 4596-4610. doi:10.1021/jo062422i

33. Smith, A. B., III; Kürti, L.; Davulcu, A. H.; Cho, Y. S.; Ohmoto, K. J. Org. Chem. 2007, 72, 4611-4620. doi:10.1021/jo062423a

34. Marsch, N.; Jones, P. G.; Lindel, T. Beilstein J. Org. Chem. 2015, 11, 1700-1706. doi:10.3762/bjoc.11.184 
35. Li, B. T. Y.; White, J. M.; Hutton, C. A. Aust. J. Chem. 2010, 63, 438-444. doi:10.1071/CH10033

36. Camp, D.; Matthews, C. F.; Neville, S. T.; Rouns, M.; Scott, R. W.; Truong, Y. Org. Process Res. Dev. 2006, 10, 814-821. doi:10.1021/op0600761

37. Egi, M.; Yamaguchi, Y.; Fujiwara, N.; Akai, S. Org. Lett. 2008, 10, 1867-1870. doi:10.1021/ol800596c

38. Kern, J. C.; Terefenko, E.; Trybulski, E.; Berrodin, T. J.; Cohen, J.; Winneker, R. C.; Yudt, M. R.; Zang, Z.; Zhu, Y.; Zhang, P. Bioorg. Med. Chem. Lett. 2009, 19, 6666-6669. doi:10.1016/j.bmcl.2009.10.008

39. Minatti, A.; Zheng, X.; Buchwald, S. L. J. Org. Chem. 2007, 72, 9253-9258. doi:10.1021/jo701741y

40. Hirai, G.; Koizumi, Y.; Moharram, S. M.; Oguri, H.; Hirama, M. Org. Lett. 2002, 4, 1627-1630. doi:10.1021/ol025852d

41. Ito, N.; Esaki, H.; Maesawa, T.; Imamiya, E.; Maegawa, T.; Sajiki, H. Bull. Chem. Soc. Jpn. 2008, 81, 278-286. doi:10.1246/bcsj.81.278

42. Chancellor, D. R.; Davies, K. E.; De Moor, O.; Dorgan, C. R.; Johnson, P. D.; Lambert, A. G.; Lawrence, D.; Lecci, C.; Maillol, C.; Middleton, P. J.; Nugent, G.; Poignant, S. D.; Potter, A. C.; Price, P. D.; Pye, R. J.; Storer, R.; Tinsley, J. M.; van Well, R.; Vickers, R.; Vile, J.; Wilkes, F. J.; Wilson, F. X.; Wren, S. P.; Wynne, G. M. J. Med. Chem. 2011, 54, 3241-3250. doi:10.1021/jm200135z

43. Hengartner, U.; Batcho, A. D.; Blount, J. F.; Leimgruber, W.; Larscheid, M. E.; Scott, J. W. J. Org. Chem. 1979, 44, 3748-3752. doi:10.1021/jo01336a002

44. Okano, K.; Okuyama, K.; Fukuyama, T.; Tokuyama, H. Synlett 2008, 1977-1980. doi:10.1055/s-2008-1077980

45. Horita, K.; Yoshioka, T.; Tanaka, T.; Oikawa, Y.; Yonemitsu, O. Tetrahedron 1986, 42, 3021-3028. doi:10.1016/S0040-4020(01)90593-9

46. Alvarez-Manzaneda, E.; Chahboun, R.; Cabrera, E.; Alvarez, E.; Alvarez-Manzaneda, R.; Meneses, R.; Es-Samti, H.; Fernández, A. J. Org. Chem. 2009, 74, 3384-3388. doi:10.1021/jo900153y

47. Anzalone, A. V.; Wang, T. Y.; Chen, Z.; Cornish, V. W. Angew. Chem., Int. Ed. 2013, 52, 650-654. doi:10.1002/anie.201205369

48. Zheng, H.; Xie, X.; Yang, J.; Zhao, C.; Jing, P.; Fang, B.; She, X. Org. Biomol. Chem. 2011, 9, 7755-7762. doi:10.1039/c1ob06138k

49. Marion, N.; Díez-González, S.; de Frémont, P.; Noble, A. R.; Nolan, S. P. Angew. Chem., Int. Ed. 2006, 45, 3647-3650. doi:10.1002/anie.200600571

\section{License and Terms}

This is an Open Access article under the terms of the Creative Commons Attribution License

(http://creativecommons.org/licenses/by/2.0), which permits unrestricted use, distribution, and reproduction in any medium, provided the original work is properly cited.

The license is subject to the Beilstein Journal of Organic Chemistry terms and conditions:

(http://www.beilstein-journals.org/bjoc)

The definitive version of this article is the electronic one which can be found at:

doi:10.3762/bjoc. 12.36 